\title{
Design and Development of Computer Aided Device for Electroluminescence
}

\author{
Dr. Ajay Kumar Mishra \\ Department of Mathematics and Computer Science, R.D. University, Jabalpur, India
}

\begin{abstract}
The evolution of technology of computer-aided design, the synergistic combination of process, device and circuit simulation and modeling tools finds its roots in bipolar technology, starting in the late 1960s, and the challenges of junction isolated, double-and triple-diffused transistors. These devices and technology were the basis of the first integrated circuits; nonetheless, many of the scaling issues and underlying physical effects are integral to IC design, even after four decades of IC development. The computer aided design supplements the excellent designing and functionality of the parts list, specifications, drawing preparations and different other things important to the topic of research. A large number of fields and sectors make user of such designs such as architecture, electronics, naval science, aerospace and automotive engineering to a greater extent. The proposed work based on a device is called a computer aided device, consisting of with PIC (peripheral interface controller) microcontroller and optical sensor, which convert the phosphor light into voltage with respect to intensity of luminescence. The luminescence obtained from phosphor is dependent on the impurity concentration of the prepared phosphor and properties of zinc sulphide doped with copper and silver. Luminescence will also depend on applied voltage and frequency. When the frequency of EL cell is increases or decreases it affect the light of phosphor. The generated light is converted to equivalent electrical signal by optical sensor and it produces the voltage at the output. This output voltage is now applied at the input of the microcontroller. It converts the data in the digital form and process to further stages. The hardware implementation is carried out based on optical sensor and widely used PIC 16F873A micro controller based analog to digital converter and parallel port.
\end{abstract}

Keywords: Computer interface, interfacing, computer aided device

\section{Introduction}

An interface is shared boundary or connection between two objects, devices or systems through which information is passed. The connection can be either physical or logical. The term is used in many fields, including Physics, Chemistry, Geology, Electronics, Computers (both hardware and software) and Telecommunications etc. in Chemistry it uses to the surface between two distinct phases in a heterogeneous mixture, and in geology it uses to a surface or anomalous layer between two different types of rocks or geological epochs.

In computer engineering, an interface can be ,The physical boundary between two subsystems or devices, A part or circuit in some subsystem that sends or receives signals to or from other systems or subsystems (e.g., a video interface or a network interface card) or Standard specifying a set of functional characteristics, common physical interconnection characteristics and signal characteristics for the exchange of signals or data. Luminescence is emission of light by chemical reactions, electrical energy, subatomic motions, or stress on a crystal. This distinguishes luminescence from incandescence, which is light emitted by a substance as a result of heating. Electroluminescence is concerned with the effects of electric field on the luminescent emission of phosphors. Electroluminescence is the more specific term and refers to the light emitted by a suitable phosphor when an electric field is applied to it. The phosphor can be in the form of a polycrystalline layer or a single crystal. The conducting electrodes, one of which should be transparent in the case of polycrystalline layers, can either be laid directly on the phosphor or separated from it by dielectric medium.

\section{Description of Block Diagram of Electrolumi- Nescence Device}

Electroluminescence device consists of different sections. These sections are represented by block diagram shown in the following figurer 1.1

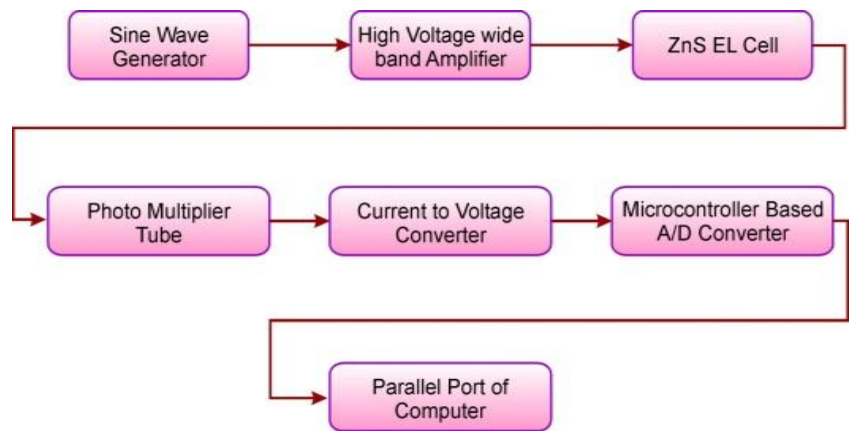
3. Title, Authors, Body Paragraphs, Sections
Headings and References

Sine Wave Generator

Sine wave generator is an electronic circuit by which wave of sine function in electronics from is generated from of few $\mathrm{Hz}$ to $1 \mathrm{GHz}$. It is redio frequency oscillator and may be colpitt's or Hartley oscillator. With the help of variation of inductance or capacitor of tank circuit required frequency from $1 \mathrm{~Hz}$ to $1 \mathrm{GHz}$ various amplitude can be generated.

\section{High Voltage Wideband Amplifier}

A audio power amplifier is an electronic amplifier that amplifies low-power audio signals The preceding stages in such a chain are low power audio amplifiers which perform tasks like pre-amplification, equalization, tone control, mixing/effects, while the input signal to an audio power 


\section{International Journal of Science and Research (IJSR) \\ ISSN (Online): 2319-7064}

Index Copernicus Value (2013): 6.14 | Impact Factor (2014): 5.611

amplifier may measure only a few hundred microwatts, its output may be tens, hundreds, or thousands of watts.

\section{ZnS EL Cell:}

In Present investigation, electroluminescence cell is prepared in lab with $\mathrm{ZnS}$ Phosphor. The ratio of different composition of activator and flux. ZnS phosphors for preparation of electroluminescence cell, firstly we prepared phosphor and then electroluminescence cell. For phosphor preparation Zinc Sulphide $(\mathrm{ZnS})$ as a base material and $\mathrm{NaCl}$ is used as a flux, the amount of flux can be varied from $2 \%$ to $20 \%$ depending upon the composition of phosphor, and the elements which play the role of activator usually are the transition metal or post transition metal such as copper, manganese, chromium, lead, bismuth and germanium. $\mathrm{ZnS}$ phosphors doped with $\mathrm{Cu}, \mathrm{Au}, \mathrm{Ag}$ and $\mathrm{Mn}$ are most common. In the present work we have used $\mathrm{CuSO}_{4} \cdot 5 \mathrm{H}_{2} \mathrm{O}$ for the doping of $\mathrm{Cu}$, and $\mathrm{AgNO}_{3}$ for the doping of $\mathrm{Ag}$ in $\mathrm{ZnS}$ phosphors, the activator concentration was varied from 100 to 5000 PPM.

\section{Photomultiplier Tube}

Photomultiplier tubes (PMT), members of the class of vacuum tubes, and more specifically vacuum phototubes, are extremely sensitive detectors of light in the ultraviolet, visible, and near-infrared ranges of the electromagnetic spectrum. These detectors multiply the current produced by incident light by as much as 100 million times (i.e., $160 \mathrm{~dB}$ ), in multiple dynode stages, enabling (for example) individual photons to be detected when the incident flux of light is very low. Unlike most vacuum tubes, these are not obsolete.

\section{Current to Voltage Converter}

The current to voltage converter, most often implemented using an operational amplifier. The current to voltage converter can be used to amplify the current output of Geiger-Müller tubes, photomultiplier tubes, accelerometers, photo detectors and other types of sensors. The current to voltage converters are used with sensors that have a current response that is more linear than the voltage response. This is the case with photodiodes where it is not uncommon for the current response to have better than $1 \%$ linearity over a wide range of light input.

\section{Microcontroller Based A/D Converter}

The name PIC initially referred to Peripheral Interface Controller PIC is a family of modified Harvard architecture microcontrollers made by Microchip Technology, derived from the PIC1650 originally developed by General Instrument's Microelectronics Division. PICs are popular with both industrial developers and hobbyists due to their low cost, wide availability, large user base, extensive collection of application notes, availability of low cost or free development tools, and serial programming (and reprogramming with flash memory) capability. In Present investigation we used PIC16F873A microcontroller, the pin diagram of PIC16F873A microcontroller are shown in figure 3.3, PIC16F873A devices are available only in 28-Pin packages, and there is three input output ports, fourteen interrupts and five analog to digital channels, operating frequency DC to $20 \mathrm{MHz}$ and Flash Program Memory $4 \mathrm{~K}$ bytes, and there is three input output ports (Port A, B, C), 128 EEPROM Data Memory bytes, two analog comparator, and 35 instruction set.

\section{Parallel port of computer:}

This port is available at computers mother board, when converted data are reached at this port it received and interface with the hardware and software. And received data are display on the monitor.

\section{Measurement of Electroluminescence of $\mathrm{ZnS}$}

For the measurement of EL brightness EL cell is prepared by selected method and it is ready to use for measurement of luminescence. In prepared cell, there are two electrodes, one from conducting glass plate and other from phosphor sample side. Frequency is applied to amplifier at the desired level and it increases voltage up to required level, when frequency and voltage are reached at certain level, then emission of EL is takes place the emission of light is connected to Photomultiplier tube (PMT) and it converts the light in the form of current and then converted to voltage by voltage to current converter. The output voltage is apply to PIC16F873A microcontroller and it convert this analog voltage to Digital voltage. The digital voltage to be interfaced with the computer by parallel port. The data of parallel port is read by VB.NET software and finally luminescence of EL cell is converted in voltage, and is obtained at the screen of the computer.

\section{Result of EL Cell}

The voltage dependence of EL brightness of $\mathrm{ZnS}$ : $\mathrm{Cu}$ (having activator concentration $3000 \mathrm{ppm}$ ) is shown in figure 5.2, 5.3, 5.4, 5.5 and 5.6 for different frequencies of the applied electric field. It can be observed from the above figure that the brightness increases with the applied voltage at a given frequency.

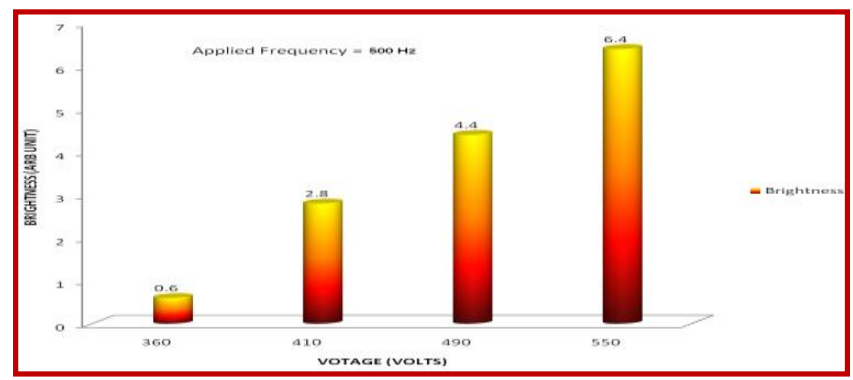

Figure 5.2: EL Brightness of Voltage Dependence of $\mathrm{ZnS}: \mathrm{Cu}$ Phosphor at $500 \mathrm{~Hz}$ Frequency

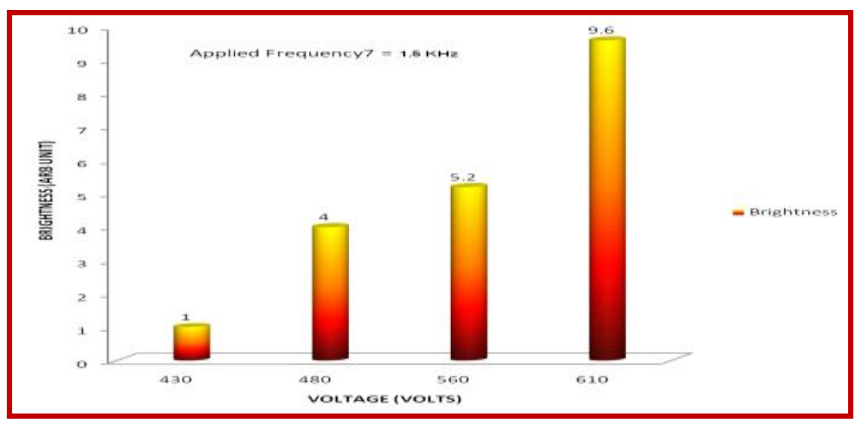

Figure 5.3: EL Brightness of Voltage Dependence of $\mathrm{ZnS}: \mathrm{Cu}$ Phosphor at $1.5 \mathrm{KHz}$ Frequency 


\section{International Journal of Science and Research (IJSR) \\ ISSN (Online): 2319-7064}

Index Copernicus Value (2013): 6.14 | Impact Factor (2014): 5.611

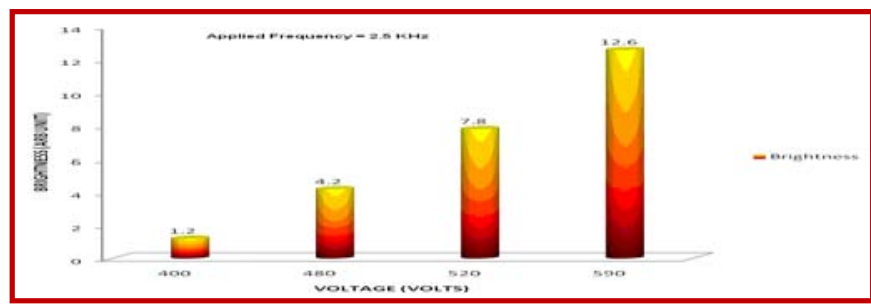

Figure 5.4: EL Brightness of Voltage Dependence of $\mathrm{ZnS}: \mathrm{Cu}$ Phosphor at $2.5 \mathrm{KHz}$ Frequency

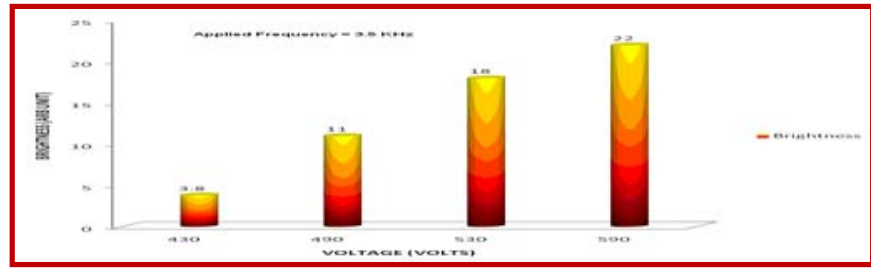

Figure 5.5: EL Brightness of Voltage Dependence of $\mathrm{ZnS}: \mathrm{Cu}$ Phosphor at $3.5 \mathrm{KHz}$ frequency

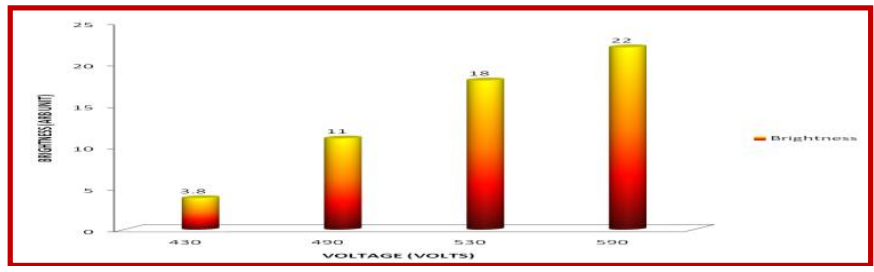

Figure 5.6: EL Brightness of Voltage Dependence of $\mathrm{ZnS}: \mathrm{Cu}$ Phosphor at $4.5 \mathrm{KHz}$ Frequency

\section{Conclusion of Investigation}

In present investigation, "Design and Development of Computer Aided Device for Study of Electroluminescence of $\mathrm{ZnS}$ Phosphor" is prepared for the measurement of Electroluminescence the device performs the following properties which are given below:

High speed, High accuracy results with highly précised output, Manual observation is be reduced, Data can be stored for long time, Output can be obtained in voltage form, Pico ammeter will not be required for the setup, The output of the electroluminescence is easy to read on computer screen, The Device required low power supply, The cost of device is low

\section{Discussion}

Design and developed computer aided device is prepared to take the measurements with different samples. When developed setup is start for the measurements, it works continuously till the photomultiplier tube is converted the luminescence of electroluminescence cell.

\section{References}

[1] Blaauw, Gerritt A.; Brooks, Jr., Frederick P. (1997), "Chapter 8.6, Device Interfaces", Computer Architecture-Concepts and Evolution, AddisonWesley, pp. 489-493, ISBN 0-201-10557-8

[2] Green, T. R. G.; Petre, M. (1996). "Usability analysis of visual programming environments: A 'cognitive dimensions' framework". Journal of Visual Languages

\section{and Computing}

7:

$131-174$

doi:10.1006/jvlc.1996.0009.

[3] David E. Boundy (October 1991). "A taxonomy of programmers". ACM SIGSOFT Software Engineering Notes 16(4) 23-30. alcor.concordia.ca.

[4] Summary of design rules from The Humane Interface

[5] "What Is an Interface". The Java Tutorials. Oracle. Retrieved 2012-05-01.

[6] "Dataproducts D-Sub 50 Parallel". Hardware Book. Retrieved 2008-01-25.

[7] "Dataproducts M/50 Parallel". Hardware Book. Retrieved 2008-01-25.

[8] Proceedings of the National Electronics Conference, Volume 17, National Engineering Conference, Inc., 1961 ; page 328

[9] Electrogenerated Chemiluminescence, Edited by Allen J. Bard, Marcel Dekker, Inc., 2004

[10] "Active Matrix Electroluminescence (AMEL)".

[11] Vidal, JJ (1973). "Toward direct brain-computer communication". Annual review of biophysics and bioengineering $\quad \mathbf{2}$ 157-80. doi:10.1146/annurev.bb.02.060173.001105.

[12] J. Vidal (1977). "Real-Time Detection of Brain Events in EEG". IEEE Proceedings 65 (5): 633-641. doi:10.1109/PROC.1977.10542.

[13] "Design of Microcontroller Based Data Acquisition Device for Process Measurement" DOSTALEK, P. \& VASEK, V., $16^{\text {th }}$ International DAAAM Symposium, ISSN 1726-9679, ISBN 3-901509-46-1.

[14] "Personal Computer Based Clinical Programming Software for Auditory Prostheses" K. Rajakumar and P. Seetha Ramaiah, Journal of Computer Science 5 (8): 589-595, 2009, ISSN 1549-3636.

[15] "Design of Intel 8751 Microcontroller-Based System for Monitoring and controller of a thermal process" Francis Enejo Idachaba, IETE Journal of Research, VOL 56, ISSUE 4, Jul-Aug. 2010.

[16] B. P. Chandra, K. K. Shrivastava, J. Phys. And Chem. Of Solid 39 (1978), 939.

[17] B. Majumdar, Studies on the Mechanoluminescence of Zinc Sulphide and other phosphors, Ph. D. Thesis Ravishanker University, Raipur 1984.

[18] R.N. Bhargava, D. Gallagherand T. Weller, J. Lumin. $60 \& 61,275$ (1994).

[19] Y. Yang, S. Xue, S. Liu, J. Hang and J. Shen, Appl. Phys. Lett, 69, 377 (1996) 